\title{
Rapid detection of Ganoderma-infected oil palms by microwave ergosterol extraction with HPLC and TLC
}

\author{
M.S. Muniroh ${ }^{\text {a }}$, M. Sariah ${ }^{\text {a,* }}$, M.A. Zainal Abidin ${ }^{\text {a }}$, N. Lima ${ }^{\text {b }}$, R.R.M. Paterson ${ }^{\text {b }}$ \\ a Department of Plant Protection, Faculty of Agriculture, Universiti Putra Malaysia, 43400 UPM Serdang, Selangor, Malaysia \\ b IBB - Institute for Biotechnology and Bioengineering, Centre of Biological Engineering, Universidade do Minho, 4710-057 Braga, Portugal
}

\section{A R T I C L E I N F O}

\section{Article history:}

Received 17 July 2013

Received in revised form 13 March 2014

Accepted 16 March 2014

Available online 26 March 2014

\section{Keywords:}

Microwave assisted extraction

Ganoderma

Ergosterol

Oil palm

TLC

HPLC

\begin{abstract}
A B S T R A C T
Detection of basal stem rot (BSR) by Ganoderma of oil palms was based on foliar symptoms and production of basidiomata. Enzyme-Linked Immunosorbent Assays-Polyclonal Antibody (ELISA-PAB) and PCR have been proposed as early detection methods for the disease. These techniques are complex, time consuming and have accuracy limitations. An ergosterol method was developed which correlated well with the degree of infection in oil palms, including samples growing in plantations. However, the method was capable of being optimised. This current study was designed to develop a simpler, more rapid and efficient ergosterol method with utility in the field that involved the use of microwave extraction. The optimised procedure involved extracting a small amount of Ganoderma, or Ganoderma-infected oil palm suspended in low volumes of solvent followed by irradiation in a conventional microwave oven at $70{ }^{\circ} \mathrm{C}$ and medium high power for $30 \mathrm{~s}$, resulting in simultaneous extraction and saponification. Ergosterol was detected by thin layer chromatography (TLC) and quantified using high performance liquid chromatography with diode array detection. The TLC method was novel and provided a simple, inexpensive method with utility in the field. The new method was particularly effective at extracting high yields of ergosterol from infected oil palm and enables rapid analysis of field samples on site, allowing infected oil palms to be treated or culled very rapidly. Some limitations of the method are discussed herein. The procedures lend themselves to controlling the disease more effectively and allowing more effective use of land currently employed to grow oil palms, thereby reducing pressure to develop new plantations.
\end{abstract}

(c) 2014 Elsevier B.V. All rights reserved.

\section{Introduction}

Palm oil is a major commodity used in ca. $30 \%$ of foods and cosmetics. Increasingly the oil is used as a biofuel and contributes considerably to the economies of many nations and particularly Malaysia and Indonesia (Paterson et al., 2013). Oil palms suffer from the major disease, basal stem rot (BSR), caused by the white rot fungus Ganoderma. According to Idris et al. (2011), 632 out of 1061 estates (59.57\%) that responded to a survey, reported incidences of BSR disease. The average incidence of BSR in Malaysia was 3.71\% with an affected area of 59,148 ha. The economic losses are between $\$ 68$ and $\$ 455$ million a year in Malaysia alone (Chong, 2012).

The disease is currently detected based on development of foliar symptoms and production of basidiomata in mature fields. However, visible symptoms indicate that the (a) palms are already at a serious stage of infection and (b) fungus has killed approximately half of the basal tissue. More effective methods to detect the disease early are

\footnotetext{
* Corresponding author. Tel.: +60 3894 8947; fax: +60 389381014.

E-mail address: muniroh_mdsaad@yahoo.com (M. Sariah).
}

required urgently so that remedial action (e.g. culling) can be taken quickly to prevent spread to healthy oil palms causing even more disease. Better control of the disease may create ecological benefits from reduced pressure to create new plantations as the yields from existing fields increase.

The Enzyme-Linked Immunosorbent Assay-Polyclonal Antibody (ELISA-PAB) and PCR have been proposed (Mohd Aswad et al., 2011), but these methods are not applicable for large scale field monitoring because they are complex, time consuming and have accuracy limitations. For example, PCR can be subjected to inhibition (Paterson, 2007a) and ELISA-PAB suffers from cross reactivity (Idris and Rafidah, 2008). Ganoderma boninense, the causal fungal pathogen of BSR in oil palm, colonises the roots and leads to an incremental increase in fungal biomass during disease development. Also, the fungus appears to colonise from one oil palm to another by producing vast numbers of spores (Sanderson, 2005). One of the common cell membrane components, ergosterol, is sufficiently specific (Mille-Lindblom et al., 2006) that it is used to quantify fungi in soil (Grant and West, 1986; Frostegard and Baath, 1996), roots (Bindler et al., 1988), cereal grains (Seitz et al., 1977), and decaying plant material (Newell et al., 1988). The compound is used to quantify ectomycorrhizae (Salmanowicz and Nylund, 1988; 
Wallander et al., 1997). Also, ergosterol in the white rot fungi Hydnum and Polyporus was correlated with growth of these fungi in oil palm in vitro (Paterson et al., 2000). Paterson (2007b) recommended the use of ergosterol to determine the levels of BSR in oil palm trunk and recent analysis of ergosterol in Ganoderma infected oil palm tissue showed a strong correlation between ergosterol concentration and disease severity, indicating the possible application of ergosterol in the quantification of BSR in palms (Mohd Aswad et al., 2011). In this study, apparently diseased and healthy oil palms were felled and assessed for disease, from none to high, by conventional methods. The symptoms correlated well with ergosterol levels, and ergosterol was undetected in the healthy palm samples. In addition, standing oil palms were assessed for disease and drilled for samples: similar results were obtained to the felled oil palms. These procedures are similar to those that would occur during normal plantation management of the disease. The method of analysis of ergosterol was chromatography which is a chemical method involving solid/liquid phase separations and more robust inherently than the biochemical methods, such as PCR and antibodies, which involve potentially more variable biochemicals such as proteins and nucleic acids.

Naturally, there are limitations to the method: It will not differentiate between the target Ganoderma and other fungi which may be present. However, no other fungi will contribute significantly to the concentration of ergosterol, as Ganoderma is the only fungus involved in this type of disease in oil palm, where a large amount of fungal biomass is produced as infection proceeds (Paterson, 2007b). Fusarium wilt causes disease of oil palms by a quite different mechanism involving production of extracellular enzymes rather than large increases in biomass. Fatal yellowing or lethal bud rot of oil palm is caused by Thielaviopsis paradoxa (teleomorph Ceratocystis paradoxa) which attacks non-lignified tissue. This disease is infrequent and will not be involved in high growth throughout the palm stem or roots as is the case with Ganoderma. The most important fungal disease in Colombia is bud rot by Phytophthora palmivora. This fungus does not cause disease by extensive growth throughout the roots or stem and by implication is limited in its effect to buds (Paterson et al., 2013). Hence, these fungi will not interfere with the ergosterol analyses. Although not a limitation per se, another issue is the concentration of ergosterol that would merit culling an oil palm, which will require careful investigations to ensure the cost-effective values are obtained.

However, the extraction method in Mohd Aswad et al. (2011) is time consuming, and requires large amounts of costly equipment and high volumes of expensive and potentially-dangerous solvents. In plantations, BSR censuses are carried out regularly and preferably at six month intervals: a robust, rapid and reliable early detection method is highly desirable for large scale BSR monitoring, which could be adapted to field analyses. A particularly desirable method would be one that could be undertaken on-site (e.g. near to an oil palm plantation).

Microwave energy has been shown to greatly accelerate a wide variety of (a) chemical reactions at up to as much as 240 times (Mingos and Baghurst, 1991) and (b) extractions of organic chemicals from various matrices (Ganzler et al., 1986; Onuska and Terry, 1993; Lopez-Avila et al., 1994). Young (1995) developed a microwave-assisted extraction (MAE) technique for analysis of ergosterol in fungi and samples contaminated with fungi. The recovery of ergosterol was more efficient than that of classical and supercritical fluid extraction methods. Thus this present study was conducted to determine the practicability of using the MAE method in monitoring BSR infections in field samples and represents the first such report.

\section{Materials and methods}

\subsection{Mycelial culture of Ganoderma}

A pure culture of G. boninense (strain UPM 13) was isolated from a basidiomata of an infected oil palm trunk in Gua Musang Felda,
Malaysia using Ganoderma selective medium (Ariffin and Idris, 1991) and the identification was confirmed by experts based on mycelial and spore morphology. The pure culture was maintained on malt extract agar (MEA) (Merck) and deposited in the culture collection of Institute of Bioscience (IBS), UPM, Malaysia as a stock culture. A mycelial disc $(0.5 \mathrm{~cm})$ from a 14-day culture was cut and grown in static $250 \mathrm{~mL}$ Erlenmeyer flasks containing $100 \mathrm{~mL}$ Malt Extract Broth (MEB) (Merck) at room temperature $\left(25 \pm 2{ }^{\circ} \mathrm{C}\right)$. The mycelium was removed from the flask after 2 weeks, rinsed with sterile distilled water, air dried and stored at $-80{ }^{\circ} \mathrm{C}$ as inocula for subsequent experiments.

\subsection{Ergosterol extraction using microwave assisted extraction}

Extraction of $G$. boninense was based on the procedure of Young (1995) with modifications. A sample of $0.5 \mathrm{~g}$ fresh weight (FW) mycelium from 2 week-old Ganoderma mycelium grown in MEB as mentioned above, was macerated in liquid nitrogen using a mortar and pestle into a powder, and transferred to a Pyrex test tube with a Teflon screw cap. Two millilitres of methanol (Merck, Chromatography grade) and $0.5 \mathrm{~mL}$ of $2 \mathrm{M}$ sodium hydroxide were added and the tube was tightly sealed. The test tubes were placed in a culture jar at the centre of a conventional microwave (Sharp Jet Convectional Grill, model TTAG A437 with a capacity of $1.5 \mathrm{ft}^{3}$ ) and subjected to various levels of microwaves that formed the basis of experiments. The solutions were left to cool and were neutralized with concentrated hydrochloric acid. Finally, the solutions were extracted three times with $2 \mathrm{~mL}$ of pentane (Fisher chemicals, analytical reagent grade). The combine pentane extracts were then evaporated to dryness by using a Buchi rotary evaporator and then dissolved in $500 \mu \mathrm{L}$ methanol for the detection of ergosterol using thin layer chromatography (TLC) and quantified using high performance liquid chromatography (HPLC) against an ergosterol standard (Sigma, purity $\geq 95.0 \%$ ).

\subsubsection{Optimisation of extraction}

To determine the optimum microwave extraction settings, different temperatures were used according to the temperature settings available on the microwave ( 40 and $70{ }^{\circ} \mathrm{C}$ ), power (medium, medium high and high) and exposure times (10, 20 and $30 \mathrm{~s}$ ) and which were tested on $0.5 \mathrm{~g}$ FW Ganoderma mycelium.

\subsubsection{Ergosterol from different weights of Ganoderma}

Freshly harvested mycelium from 2 week old Ganoderma mycelium grown in MEB as mentioned above $(0.025,0.05,0.10,0.20,0.40,0.60$, 0.80 and $1.00 \mathrm{~g}$ ) was used for the ergosterol extraction to determine the linearity of response of the extraction.

\subsubsection{Ergosterol from different weights of oil palm}

The infected tissues were drilled from 15 infected palms obtained from the Gua Musang Felda plantation and exhibiting stage 3 of BSR infection. The level of infection was determined by the disease pictorial key developed by Mohd Aswad et al. (2011), characterised by unopened spear leaves and basidiomata of the fungus appearing at the trunk or roots near soil level; infected drilled tissues appeared dark brown with a strong fermented and rancid odour. Different weights of three sub-samples from each palm $(0.25,0.50,1.00,1.50,2.00,2.50,3.00$, 3.50 and $4.00 \mathrm{~g}$ ) were macerated in liquid nitrogen and ergosterol extracted based on the predetermined optimised microwave settings. The identification of ergosterol was achieved by HPLC diode array detection and TLC.

\subsubsection{Comparison between different methods of ergosterol extraction}

Comparisons were made between the MAE, the non-alkaline extraction (NAE) (Gong et al., 2001), and the ultra-sonication extraction (USE) methods (Yuan et al., 2007) with $0.5 \mathrm{~g}$ FW of Ganoderma mycelium. 


\subsection{Detection and quantification of ergosterol}

\subsubsection{Thin layer chromatography}

Six microlitres of the $100 \mu \mathrm{g} \mathrm{mL}{ }^{-1}$ standard ergosterol (Sigma, purity $\geq 95.0 \%$ ) and the extracted ergosterol was spotted on RP-18 Silica coated TLC plates (Merck, $20 \times 20 \mathrm{~cm}$ ) with a micropipetter (Eppendorf) with a $10 \mathrm{~mm}$ space between each spot. The spots were then air dried for $5 \mathrm{~min}$ before development. The plates were developed in $25 \mathrm{~mL}$ of $\mathrm{n}$-hexane/ ethyl acetate $(75 / 25 ; \mathrm{v} / \mathrm{v})$ for approximately $60 \mathrm{~min}$ in a flat bottom developing chamber (CAMAG). The plates were dried for $5 \mathrm{~min}$ and viewed under a UV lamp at $365 \mathrm{~nm}$. TLC detection was undertaken in duplicate for all samples. The identification of ergosterol was based on comparison with the $R_{\mathrm{f}}$ value with the ergosterol standard and the concentrations were obtained from the HPLC analyses.

\subsubsection{High performance liquid chromatography}

An Agilent 1100 series HPLC equipped with a Diode Array Detector (G1315B), a pump (G1311A), and an autosampler (G1313A) was used for quantification of ergosterol using an Ascentis express $2.7 \mu \mathrm{C} 18$ reverse-phase column (Supelco, USA). Operating conditions consisted of an isocratic HPLC-grade methanol mobile phase at a flow rate of $1 \mathrm{~mL} \mathrm{~min}^{-1}$. The mobile phase was degassed for $30 \mathrm{~min}$ in an ultrasonicator (Cole-palmer) at full power. The UV detection was at $282 \mathrm{~nm}$ and injection volume of $10 \mu \mathrm{L}$ per sample was set for quantification. The average retention time of ergosterol was $7 \mathrm{~min}$. An ergosterol standard was prepared for constructing the standard curve. The ergosterol peak was determined by comparison of the retention time and UV absorbance at $282 \mathrm{~nm}$ against the pure ergosterol standard. The ergosterol concentration for each run was determined by comparison against the ergosterol standard calibration curve. All ergosterol concentrations are reported on a per unit weight basis and each sample was analysed in triplicate.

\section{Results}

\subsection{Ergosterol extraction using microwave assisted extraction}

\subsubsection{Optimisation of ergosterol extraction}

The HPLC responses (peak areas) were checked for linearity within the level 50-120 $\mu \mathrm{g}$ ergosterol standard. The peaks were correlated with ergosterol concentrations, which gave a good correlation coefficient $\left(R^{2}\right)$ of 0.9978 . The ergosterol standard peak was well resolved in all runs. The concentrations of ergosterol for the different microwave settings are illustrated in Fig. 1. The setting of medium high at $70{ }^{\circ} \mathrm{C}$ for 30 s exposure time was the most efficient, which resulted in the highest concentrations of ergosterol extracted from $0.5 \mathrm{~g}$ fresh weight of Ganoderma mycelium.

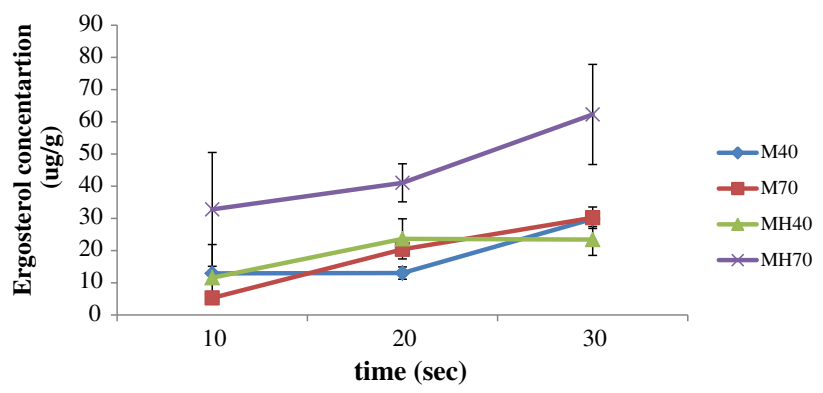

Fig. 1. Ergosterol concentration from $0.5 \mathrm{~g}$ fresh weight of Ganoderma boninense mycelium with various microwave temperatures, power levels and exposure times ( $\mathrm{M} 40=$ medium, $40{ }^{\circ} \mathrm{C}$, M70 $=$ medium, $70{ }^{\circ} \mathrm{C}$, MH40 = medium high, $40{ }^{\circ} \mathrm{C}$, MH70 = medium high, $70{ }^{\circ} \mathrm{C}$ ). Bars represent means $\pm \mathrm{SD}$ (error bar) of triplicate determinations.

\subsubsection{Ergosterol from different weights of Ganoderma}

Ergosterol concentration increased proportionally with mycelial biomass (Fig. 2). The lowest and the highest Ganoderma biomass of $0.025 \mathrm{~g}$ and $1.0 \mathrm{~g}$ resulted in the lowest and highest ergosterol concentration of $22.70 \mu \mathrm{g} \mathrm{g}^{-1}$ and $64.00 \mu \mathrm{g} \mathrm{g}^{-1}$ respectively. The intensity of the ergosterol spots detected on the TLC plates increased proportionately with the increase in mycelial biomass (and hence ergosterol) with the retention factor $\left(R_{\mathrm{f}}\right.$ value $)$ of 0.68 .

\subsubsection{Ergosterol from different weights of oil palm}

To determine the efficiency of extraction by the microwave method on actual oil palm samples, the amounts of ergosterol from different weights of Ganoderma infected oil palm and MAE ergosterol HPLC chromatogram of infected oil palm tissue are provided in Fig. 3. The lowest and the highest biomass of $0.25 \mathrm{~g}$ and $4.00 \mathrm{~g}$ resulted in the lowest and highest ergosterol concentrations of $2.20 \mu \mathrm{g} \mathrm{g}^{-1}$ and $6.60 \mu \mathrm{g} \mathrm{g}^{-1}$ respectively.

\subsubsection{Comparison between different methods of ergosterol extraction}

The MAE extraction method was the most efficient compared to the NAE and USE methods. The amounts extracted from $0.50 \mathrm{~g}$ fresh weight of Ganoderma mycelium with MAE $\left(62.06 \mu \mathrm{g} \mathrm{g}^{-1}\right)$ were significantly higher than the USE ( $\left.9.63 \mu \mathrm{g} \mathrm{g}^{-1}\right)$ and NAE $\left(7.34 \mu \mathrm{g} \mathrm{g}^{-1}\right)$ methods, whereas the values for USE and NAE were not significantly different. In addition, the TLC analysis also showed the highest intensity of spots produced with MAE and that the size of the spots was proportional to the concentration of ergosterol (Fig. 4). Comparisons of experimental settings between MAE and NAE showed that MAE required shorter time than NAE method and more samples can be extracted within a particular period of time (Table 1 ).

\section{Discussion}

Ergosterol is a primary sterol in cell membranes of filamentous fungi and is absent, or present as a minor component, in the majority of higher plants (Madonna et al., 2001). The present work indicated that a microwave extraction of medium high power at $70{ }^{\circ} \mathrm{C}$ provided the optimal extraction of ergosterol from G. boninense mycelium (Fig. 1). In addition, there was a direct relationship between the weight of mycelium and the concentration of ergosterol (Fig. 2). These results indicated that the method was suitable for analyzing samples of oil palm comparable with that of Mohd Aswad et al. (2011) in the earlier report. There was a direct relationship between the weight of infected oil palm samples and the ergosterol concentration (Fig. 3).

Recent work indicates that ergosterol cannot be detected in healthy oil palms (Mohd Aswad et al., 2011; Toh Choon et al., 2012; Chong, 2012) and that ergosterol analysis is a valid diagnostic method to detect BSR. The methods used for analysis of ergosterol in other systems were frequently based on Seitz et al. (1977, 1979), and involved methanolic extraction, alkaline saponification, pentane extraction and reversed

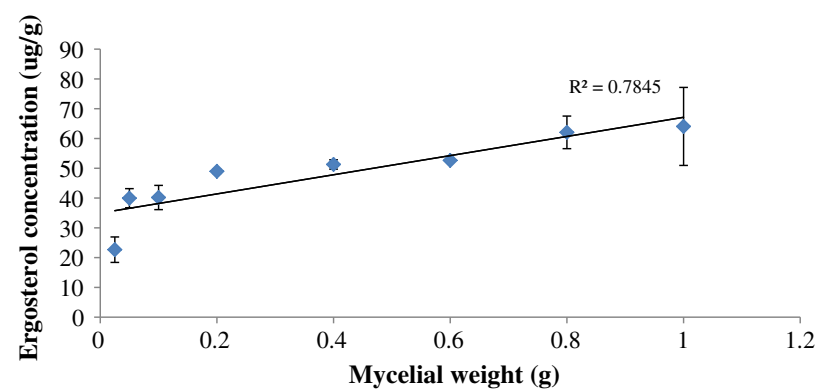

Fig. 2. Effect of sample weights of Ganoderma boninense mycelium on ergosterol concentration. Bars represent means \pm SD (error bar) of triplicate determinations. As can be determined there was a direct relation between mycelium weight and ergosterol concentration. 
a
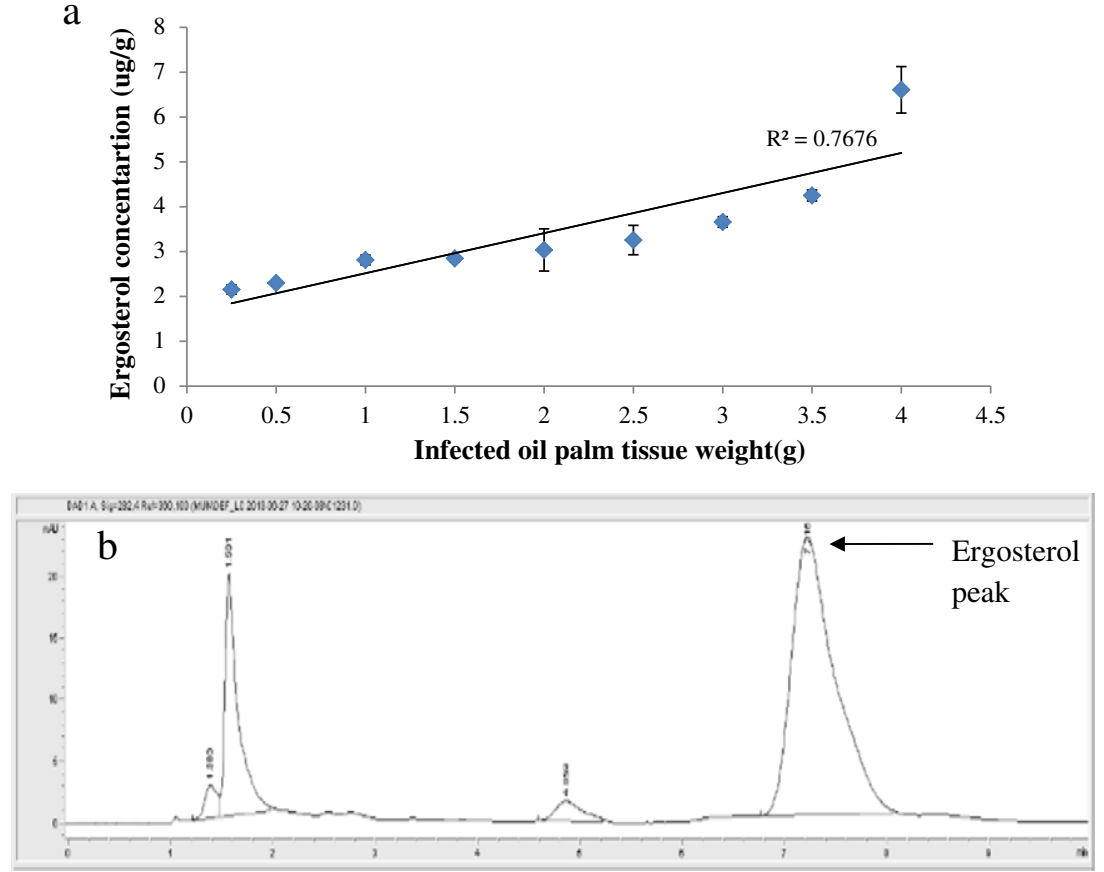

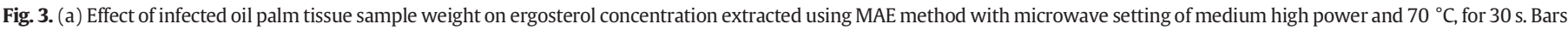

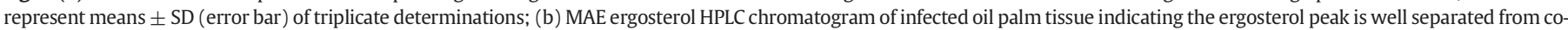

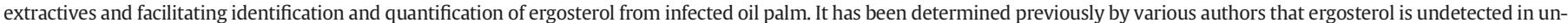
infected oil palm (see Discussion in the present paper).

phase high performance liquid chromatographic (HPLC) separation with ultraviolet (UV) detection at $282 \mathrm{~nm}$. Some modifications reported include combinations of methanolic extraction and saponification (Newell et al., 1988; Zill et al., 1988; Schwadorf and Muller, 1989); the use of $\mathrm{CO}_{2}$ supercritical fluid extraction (SFE), and supercritical fluid chromatography (Young and Games, 1993). Young (1995) developed the microwave-assisted extraction (MAE) technique for analysis of ergosterol in fungi and samples contaminated by fungi. Ergosterol recoveries using classical extraction and supercritical fluid extraction methods were lower than that of MAE.

The basic principle of the MAE protocol is that ergosterol can be extracted from fungal membranes by the microwave effect which evaporates and generates tremendous pressure on the cell wall due to swelling of the cells (Wang and Weller, 2006). The pressure pushes the cell wall from inside, broadening and eventually breaking it, which aids leaching out of the active constituents from the ruptured cell to the surrounding solvent therefore improving the yield of phytoconstituents. Microwave power and irradiation time were the two factors which influence extraction to a great extent. In this present study, the optimum setting for the MAE technique was $70{ }^{\circ} \mathrm{C}$ with medium high power and 30 s exposure time (Fig. 1). A (a) higher and (b) lower microwave temperature and power resulted in (a) the leaking of the solvent from the tube, and (b) less ergosterol respectively. A combination of low or moderate power with longer exposure may be useful, but high power with prolonged exposure involves the risk of thermal degradation (Mandal et al., 2007).

As mentioned in the Introduction, the extraction will include the ergosterol of all the fungi that were present in the initial sample and is a potential limitation. However, it was shown that ergosterol was undetected in healthy oil palms which is an indication of the utility of the method in that any chance contamination will not affect the results. In addition, Ganoderma is the only fungus that causes this type of disease and is by far the most prevalent disease of oil palms in SE Asia. Therefore, the level of ergosterol is likely to be related directly to the amount of oil palm rot and not the presence of other fungi. An issue that requires addressing is at what concentration of ergosterol will a decision to cull infected oil palm be made? This will be determined by further studies in the field which correlate ergosterol detection with existing, later parameters used to make the decision to cull (e.g. presence of basidiomata). Furthermore, blind sampling would provide useful information in future studies now that correlations between disease and ergosterol have been made in the current and previous papers. A certain representative number of oil palms from a field could be selected randomly and analysed for ergosterol using drilling of standing trees (Mohd Aswad et al., 2011).

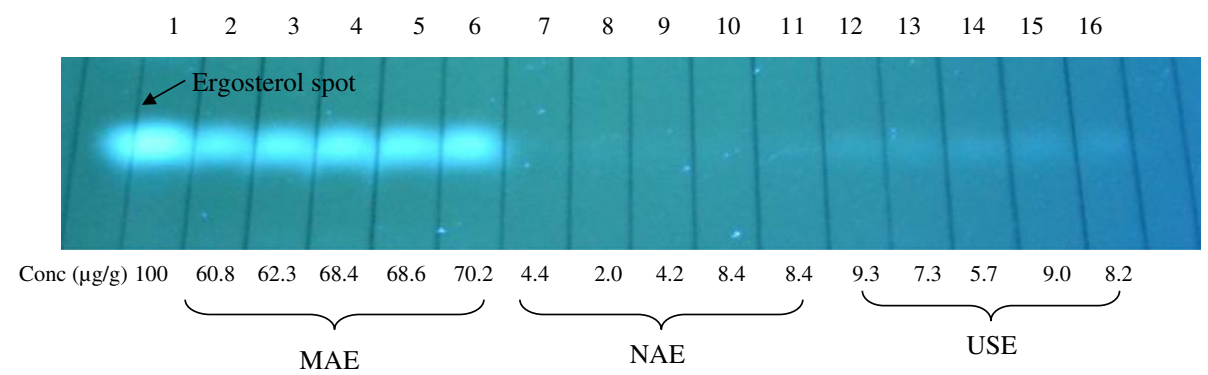

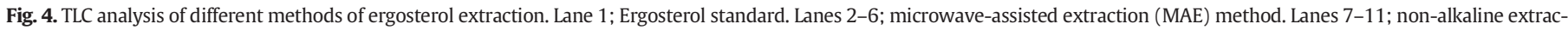

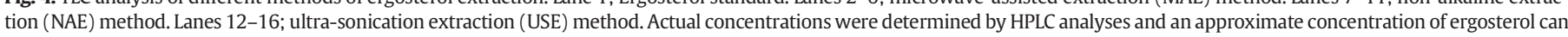
be obtained from the size of the spots on the TLC plate. 
Table 1

Comparisons of efficiency of ergosterol extraction based on MAE and NAE method.

\begin{tabular}{|c|c|c|}
\hline Experimental setting & Microwave-assisted extraction (MAE) & Non-alkaline extraction method (NAE) (Mohd Aswad et al., 2011) \\
\hline Number of sample/batch & 10 samples & 1 sample \\
\hline Volume of solvent used/sample & $4 \mathrm{~mL}$ & $6 \mathrm{~mL}$ \\
\hline Minimum weight of infected tissue/sample & $1.0 \mathrm{~g}$ & $3.0 \mathrm{~g}$ \\
\hline Time required/batch (extraction until TLC/HPLC loading) & $25 \mathrm{~min}$ & $40 \mathrm{~min}$ \\
\hline Recovery rate base on $100 \mu \mathrm{g}$ ergosterol standard & $62 \%$ & $7 \%$ \\
\hline
\end{tabular}

These palms could then be monitored for subsequent infection to determine the predictive capabilities of the method.

Another important fact about the MAE protocol was that it only involved the use of methanol avoiding other hazardous organic solvents. In addition, only small samples are required which is advantageous. This study also demonstrated a strong correlation between ergosterol concentration and the $G$. boninense mycelial biomass or Ganoderma infected palm tissues, indicating that ergosterol concentration increased directly with the increase of mycelial biomass. Thus, the ergosterol method as described herein confirms that it is a major advance in the estimation of fungal biomass (Mille-Lindblom et al., 2004) and applies equally to determining the compound in oil palm. The MAE technique was the most efficient, gave the highest ergosterol yields, provided higher extraction efficiency, took less time and was less labour intensive (Table 1). Finally, the applicability of TLC means that the procedure is effectively portable and could be undertaken on site (e.g. in a motor vehicle situated near a plantation) for particularly rapid results.

\section{Conclusion}

In conclusion, a novel protocol for ergosterol extraction from Ganoderma infected oil palm tissue has been developed. Chromatographic methods are more robust than other biologically-based methods such as PCR. This techniques is more convenient than other ergosterol methods in terms of time for sample preparation, cost, and sample size as only a small sample size was needed for the extraction, more samples can be extracted. This would enable the efficient analysis of a large number of field samples during BSR surveys. Semiquantitative TLC analysis is recommended as a simple and rapid detection method in the field where an HPLC may not be available. More effective disease management means that existing plantations will be more economic and, for example, reduce the pressure on converting new land to oil palm plantations with potential environmental benefits.

\section{Acknowledgement}

This project was supported by the Fundamental Research Grant Scheme (FRGS), administered through the Ministry of Higher Education, Malaysia (Grant No: 5524175).

\section{References}

Ariffin, D., Idris, A.S, 1991. A selective medium for the isolation of Ganoderma from diseased tissues. In: Yusof, B., et al. (Eds.), Proceedings of the 1991 PORIM International Palm Oil Conference - Progress, Prospects and Challenges Towards the 21st Century Module 1, Agriculture. Palm Oil Research Institute of Malaysia, Bangi, Selangor, Malaysia, pp. 517-519.

Bindler, G.N., Piadé, J.J., Schulthess, D., 1988. Evaluation of selected steroids as chemical markers of past or presently occurring fungal infections on tobacco. Beitr. Zur Tabakforschung Int. 14, 127-134.

Chong, K.P., 2012. An evaluation of Ganoderma fungal colonisation using ergosterol analysis and quantification. The Planter 88, 311-319.

Frostegard, A., Baath, E., 1996. The use of phospholipid fatty acid analysis to estimate bacterial and fungal biomass in soil. Biol. Fertil. Soils 22, 59-65.

Ganzler, K., Salgo, A., Valko, K., 1986. Microwave extraction. A novel sample preparation method for chromatography. J. Chromatogr. 371, 299-306.

Gong, P., Guan, X., Witter, E., 2001. A rapid method to extract ergosterol from soil by physical disruption. Appl. Soil Ecol. 17, 285-289.

Grant, W.D., West, A.W., 1986. Measurement of ergosterol, diaminopimelic acid and glucosamine in soil: evaluation as indicators of microbial biomass. J. Microbiol. Methods 6 , 47-53.
Idris, A.S., Rafidah, A.R., 2008. Polyclonal Antibody for Detection of Ganoderma. MPOB Information Series, http://palmoilis.mpob.gov.my/publications/TOT/TT-405.pdf 2008, (JUNE, 21/2/14)

Idris, A.S., Mior, M.H.A.Z., Maizatul, S.M., Kushairi, A., 2011. Survey on status of Ganoderma disease of oil palm. Proc. Of the PIPOC 2011 International Palm Oil Congress - Agriculture Conference. MPOB, Bangi, pp. 235-238.

Lopez-Avila, V., Young, R., Beckert, W.F., 1994. Microwave-assisted extraction of organic compounds from standard reference soils and sediments. Anal. Chem. 66 (7), 1097-1106.

Madonna, A.J., Voorhees, K.J., Hadfield, T.L., 2001. Rapid detection of taxonomically important fatty acid methyl ester and steroid biomarkers using in situ thermal hydrolysis/ methylation mass spectrometry (THM-MS): implications for bioaerosol detection. J. Anal. Appl. Pyrolysis 61, 65-89.

Mandal, V., Mohan, Y., Hemalatha, S., 2007. Microwave assisted extraction - an innovative and promising extraction tool for medicinal plant research. Pharmacogn. Rev. 1 (1), 7-18.

Mille-Lindblom, C., Von Wachenfeldt, E., Tranvik, L.J., 2004. Ergosterol as a measure of living fungal biomass: persistence in environmental samples after fungal death. J. Microbiol. Methods 59, 253-262.

Mille-Lindblom, C., Fisher, H., Tranvik, L.J., 2006. Litter associated bacteria and fungi - a comparison of biomass and communities across lakes and plant species. J. Freshw. Biol. 51, 730-741

Mingos, D.M.P., Baghurst, D.R., 1991. Applications of microwave dielectric heating effects to synthetic problems in chemistry. Chem. Soc. Rev. 20,1-47.

Mohd Aswad, A.W., Sariah, M., Paterson, R.R.M., ZainalAbidin, M.A., Lima, N., 2011. Ergosterol analyses of oil palm seedlings and plants infected with Ganoderma. Crop. Prot. 30, 1438-1442.

Newell, S.Y., Arsuffi, T.L., Fallon, R.D., 1988. Fundamental procedures for determining ergosterol content of decaying plant material by liquid chromatography. Appl. Environ. Microbiol. 54, 1876-1879.

Onuska, F.I., Terry, K.A., 1993. Extraction of pesticides from sediments using a microwave technique. Chromatographia 36, 191-194.

Paterson, R.R.M., 2007a. Internal amplification controls have not been employed in diagnostic fungal PCR hence potential false negative results. J. Appl. Microbiol. $102,1-10$.

Paterson, R.R.M., 2007b. Ganoderma disease of oil palm - a white rot perspective necessary for integrated control. Crop. Prot. 26, 1369-1376.

Paterson, R.R.M., Holderness, M., Kelley, J., Miller, R., O'Grady, E., 2000. In vitro biodegradation of oil-palm stem using macroscopic fungi from South East Asia: a preliminary investigation. In: Flood, J., Bridge, P.D., Holderness, M. (Eds.), Ganoderma Diseases of Perennial Crops. CABI Publishing, Wallingford, UK, pp. 129-138.

Paterson, R.R.M., Sariah, M., Lima, N., 2013. How will climate change affect oil palm fungal disease. Crop. Prot. 46, 113-120.

Salmanowicz, B., Nylund, J.E., 1988. High performance liquid chromatography determination of ergosterol as a measure of ectomycorrhizae infection in Scots pine. Eur. J. For. Pathol. 18, 291-298.

Sanderson, F.R., 2005. An insight into spore dispersal of Ganoderma boninense on oil palm. 159, 139-141.

Schwadorf, K., Muller, H.M., 1989. Determination of ergosterol in cereals mixed feed components and mixed feeds by liquid chromatography. J. Assoc. Off. Anal. Chem. 72, 457-462.

Seitz, L.M., Mohr, H.E., Burroughs, R., Sauer, D.B., 1977. Ergosterol as an indicator of fungal invasion in grains. Cereal Chem. 54, 1207-1217.

Seitz, L.M., Sauer, D.B., Burroughs, R., Mohr, H.E., Hubbard, J.D., 1979. Ergosterol as a measure of fungal growth. J. Phytopathol. 69, 1202-1203.

Toh Choon, R.L., Sariah, M., Siti Mariam, M.N., 2012. Ergosterol from the soilborne fungus Ganoderma boninense. J. Basic Microbiol. 52, 608-612.

Wallander, H., Massicotte, H.B., Nylund, J.E., 1997. Seasonal variation in protein, ergosterol and chitin in five morphotypes of Pinus sylvestris L. ectomycorrhizae in a mature swedish forest. Soil Biol. Biochem. 29, 45-53.

Wang, L., Weller, C.L., 2006. Recent advances in extraction of nutraceuticals from plants. Trends Food Sci. Technol. 17, 300-312.

Young, J.C., 1995. Microwave-assisted extraction of the fungal metabolite ergosterol and total fatty acids. J. Agric. Food Chem. 43 (11), 2904-2910.

Young, J.C., Games, D.E., 1993. Supercritical fluid extraction and supercritical fluid chromatography of the fungal metabolite ergosterol. J. Agric. Food Chem. 41, 577-581.

Yuan, J.P., Hai Wang, J., Liu, X., Cong Kuang, H., Yan Zhao, S., 2007. Simultaneous determination of free ergosterol and ergosteryl esters in Cordyceps sinensis by HPLC. Food Chem. 105, 1755-1759.

Zill, G., Engelhardt, G., Wallniifer, P.R., 1988. Determination of ergosterol as a measure of fungal growth using Si 60 HPLC. Z. Lebensm. Unters. Forsch. (Eur. Food Res. Technol.) $187,246-249$. 